\title{
Risk and Crisis Communication about Invisible Hazards
}

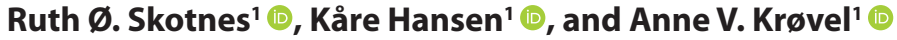

1. NORCE Norwegian Research Centre, Norway

\begin{abstract}
This article discusses differences between invisible and visible hazards, and how these differences can affect risk and crisis communication. Invisible hazards are risks that we cannot see, and often cannot touch, taste, nor smell. Examples are COVID-19, radon gas, mold spores, or asbestos fibers. Invisible hazards are often uncertain, complex, and ambiguous risk problems. Results from a Norwegian study show that authorities need to be aware of the possible differences in risk perception among authorities, stakeholders, and the general public. Involving citizens, creating trust, and being honest is important for all risk and crisis communication. However, the less we know about a hazard, the more we need to rely on others to make decisions, and consequently trust is particularly important when dealing with invisible hazards.
\end{abstract}

KEYWORDS: sensemaking, narratives, COVID-19, crisis communication, health communication

\section{ACKNOWLEDGMENT}

The project was funded by the Regional Research Fund Western Norway, which is part of the Norwegian Research Council.

Invisible hazards cannot be perceived through our senses, and they can have unclear causes and consequences. Examples are pandemics, such as COVID-19 (caused by SARS-CoV-2CV virus), radon gas, mold spores and other indoor particulate

CONTACT Ruth $\varnothing$. Skotnes (D) - E-mail: ruth.skotnes@uis.no • NORCE Norwegian Research Centre • Prof. Olav Hanssensvei 15 • 4021 Stavanger, Norway 
matter, asbestos fibers, gas leaks, and chemicals in food and feed. These risks can have sudden, direct consequences (such as COVID19 and gas leaks from plants or refineries) or delayed, long-term consequences (such as radon, asbestos, mold spores, and chemicals in food and feed). Communicating about these risks poses the dilemma of providing sufficient information without causing unnecessary concern.

The purpose of communication about risk is to provide people with the insights they need to make decisions or judgments that reflect the best available knowledge and their own preferences. All people exposed to risk should have enough information to cope with risk situations (Aven \& Renn, 2010).

This article discusses the differences between invisible and visible hazards and how these differences can affect risk and crisis communication. The discussion is based on results from a research project (Skotnes et al., 2020) studying risk and crisis communication about invisible hazards in Norwegian municipalities (local authorities), in addition to examples from the Norwegian government's (central authorities) risk and crisis communication about COVID-19. The aim of the article is to show that communicating about invisible hazards can entail challenges different from those of visible hazards, and that it is important for risk and crisis communicators to be aware of the complexity, uncertainty, and ambiguity that characterize invisible hazards.

\section{Literature Review}

According to Renn (2006), all risk communication must be tailored toward the three challenges of complexity, uncertainty, and ambiguity. Complexity refers to the difficulty of identifying and quantifying causal links between a multitude of potential causal agents and specific effects. Uncertainty refers to the difficulty of predicting the occurrence of events, and/or their consequences, based on incomplete or invalid databases. Ambiguity refers to different views related to the relevance, meaning, and implications of the basis for the decision-making (i.e., interpretative ambiguity), or the values to be protected and the priorities to be made (i.e., normative ambiguity) (Aven \& Renn, 2010). Ambiguity means 
that identical behavior or statements will be assessed entirely differently by different groups (Renn, 2006).

The type of invisible hazards that we discuss in this article can be characterized as uncertain, complex, and ambiguous risk problems. Opinions often differ greatly on these issues because people have different visions of the world and the future. These divisions include strong beliefs about the necessity or reasonableness of taking or rejecting specific risks. Communicating about ambiguities is not easy, as in such a controversy, each side is convinced to have the truth on its side and views any possible balanced coverage with distrust (Renn, 2006).

In this section, we provide a review of the research literature used as a theoretical framework for this article. First, we define the concepts of invisible hazards and risk and crisis communication. Then, we provide a short review of literature about risk perception, social amplification and attenuation of risk, and trust.

\section{Invisible Hazards}

Invisible (or hidden) hazards are risks that we cannot see, and often cannot touch, taste, nor smell. The hazards are unobservable; hence, people can lack the sensory perception of danger related to these hazards. When we are confronted with invisible hazards, we must depend upon information provided by third parties.

The coronavirus 2 (SARS-CoV-2CV), which causes the disease COVID-19, is a clear example of an invisible hazard. The COVID19 crisis is an urgent threat to societies' basic structures and fundamental values and is a very complex and creeping megacrisis (Boin et al., 2020; Christensen \& Lægreid, 2020). The UN General Secretary labeled the virus a "threat to humanity," and the virus has been fought with draconian measures, closing down whole countries, regions, and municipalities. During the COVID-19 crisis major decisions have been taken under extreme time pressure, and deep complexity and uncertainty regarding the cause of the crisis, how the crisis will develop, and what the possible means and measures are (Christensen \& Lægreid, 2020), have been constantly in mind. The risk of the virus/disease and the measures taken to fight it have been heavily debated in national and international media. 
In a different example of an invisible hazard, Hevey (2017) found that a core challenge for communicating about radon risk and promoting radon remediation relates to the fact that the risk is inherently perceived as either low or simply non-existent. Many people underestimate the seriousness or long-term health effects of radon exposure. Furthermore, even when individuals are informed that their homes have high radon levels and are made aware of the consequent health threats, remediation rates are still low. Radon is a colorless, odorless, and tasteless gas. Consequently, there is an absence of sensory cues to alert people to the risk. In general, at low levels of risk, people can easily dismiss it as too small to worry about as they see any consequences as unlikely to occur.

A third example of an invisible hazard is indoor particulate matter (PM) exposure. According to Schleibinger et al. (2004), microbial damage in indoor areas is most frequently caused by molds and bacteria. Spores of molds and bacteria may become airborne and are therefore ubiquitous. They can enter indoor areas by passive ventilation or by ventilation systems. Schleibinger et al. state that infections by molds and bacteria are very rare, but persons with an immunodeficiency are especially susceptible to fungal infections. Overall, the dose relationship between the concentration of microbial particles mentioned and any adverse health effects described is not very well established, and, therefore, guidelines concerning microbial products indoors are sparse, and most are not scientifically sound. According to Hallman (2016), the invisibility of PM matters, and it represents a key issue in communicating the risk of indoor PM exposure. However, it can be difficult for people to make the link between an invisible cause and a later, invisible effect.

\section{Risk Communication versus Crisis Communication}

According to Lofstedt (2003), risk communication is best described as the flow of information and risk evaluations back and forth between academic experts, regulatory practitioners, interest groups, and the public. According to the Norwegian Directorate for Civil Protection and Emergency Planning, risk communication is about something that might happen, while 
crisis communication is about something that has already happened (DSB, 2014). According to Cairns et al. (2013), risk communication is not an instructive instrument; it is probably better understood as a discourse-the exchange of ideas between various stakeholders about something that might or might not become a threat in the future.

However, there is not always such a clear distinction between risk communication and crisis communication. Communication becomes crisis communication only when an incident turns into a crisis and people become worried and frightened. With good risk communication, it may, in some cases, be possible to avoid a crisis even if an incident (such as finding radon, asbestos, or mold in buildings) occurs.

However, Fischoff (1995) also points out that avoiding all conflict is not realistic, nor even a legitimate goal for risk communication. The best-case scenario for risk communication is having fewer, but better, conflicts. Some conflicts could be avoided by preventing needless misunderstandings, others by forestalling unacceptable projects. Those that remain would then be focused on real issues. Most importantly, risk communication must be taken seriously; one cannot expect to quiet a raging controversy with a few hastily prepared messages.

\section{Risk Perception}

The psychometric paradigm (e.g., Slovic et al., 1978; Tversky \& Kahneman, 1974) is noted as a landmark in research about public attitudes toward risk. The basis of this model is that individuals subjectively define risk and that the risk definitions may be influenced by a range of cultural, organizational, psychological, and social factors. People create mental models (i.e., they try to make sense of the world by creating meaning based on whatever information they have available) (Hallman, 2016; Slovic et al., 1980; Weick, 2001). Perception can be defined as "people's beliefs, attitudes, judgments, and feelings, as well as the wider social or cultural values and dispositions that people adopt, toward hazards and their benefits" (Hevey, 2017).

Attitude can be shaped by several factors, such as whether the risk is observable or unobservable, whether the risk causes 
fear/dread, whether the risk is known or unknown, whether the risk feels controllable or uncontrollable, and so forth. Slovic et al. (1980) found that unobservability can affect risk perception, together with other risk factors (i.e., familiarity, knowledge, and delayed effect). Sjöberg (2004), on the other hand, found that novelty did not seem to be very important in assessing perceived risk and found that other factors such as possible interference with nature and the severity of a hazard's possible consequences played a larger role. Hence, the reaction to a hazard is not the same in every person. Individual characteristics can affect the importance of some dimensions and result in quite different judgments of risk (Savadori et al., 2004).

Several well-established cognitive heuristics ("mental shortcuts") impact our risk perception, which impedes appropriate behavioral responses (Hevey, 2017; Slovic et al., 1980). An example is the affect heuristic. According to Slovic et al. (2007), in the process of making a judgment or decision, people consult or refer to an "affect pool" containing all the positive and negative tags consciously or unconsciously associated with the representations. When a negative feeling is linked to an image of a future outcome it sounds an alarm. However, when a positive feeling is associated with the outcome image, it becomes a beacon of incentive.

A major problem in risk communication is tailoring the content of the communication process to the interests and concerns of the different social and cultural groups within a society, thus risk communicators need a better understanding of peoples' concerns and perceptions of risk (Aven \& Renn, 2010).

\section{Social Amplification and Attenuation of Risk}

The theory of social amplification of risk states that hazards interact with psychological, social, institutional, and cultural processes in ways that may amplify or attenuate public responses to the risk or risk event. Behavioral patterns can, in turn, generate secondary social or economic consequences, but may also act to increase or decrease the physical risk itself (J. X. Kasperson \& Kasperson, 2005). Specific biases are evident, and people can often either overestimate or underestimate a risk (Slovic et al., 1980). 
As an example, during the last decade, several invisible hazards that led to food and feed scares were reported in the media, such as BSE, acrylamide, aspartame, and melamine milk. According to Fjaeran \& Aven (2019), this has led to risk amplification and public distrust in regulatory bodies and food industries. The Social Amplification of Risk Framework (SARF), which was introduced by R. E. Kasperson et al. in 1988, provides a description of how and why people can respond in this way and explains how risks that were assessed by experts as low risks can still produce significant public concern that often has significant societal impacts (Fjaeran \& Aven, 2019).

Attenuation, on the other hand, involves weakening or decreasing the importance or "volume" of certain risk signals and symbols (Fjaeran \& Aven, 2019). As an example, unrealistic optimism occurs when individuals have unreasonably low estimates of their own susceptibility to harm. For example, Weinstein et al. (1988) found that people who did not test for radon in a highrisk area in the U.S. held "optimistic biases," whereby they underestimated the risks associated with their own exposure to radon. According to R. E. Kasperson (2012), low-level radiation risks from natural sources and medical exposures are often attenuated and underrated, whereas radiation risks from nuclear power facilities may be amplified. Attenuation of risk can be important in that it allows individuals to cope with the multitude of risks and risk events encountered daily. However, it may also lead to potentially serious consequences from underestimation and under-response (Fjaeran \& Aven, 2019; R. E. Kasperson et al., 1988).

The SARF Framework has been criticized for implying that it is possible to define a benchmark "real" risk that is determined by experts and around which public risk perceptions can subsequently become amplified. This objectification of risk is particularly problematic when there are high levels of scientific uncertainty and a lack of consensus about the nature of risk and its impacts. Urquhart et al. (2017) found that risk assessment is a socially mediated, relational, and incremental process with experts drawing on a range of official, anecdotal, and experiential sources of information, as well as references to past events, to assemble a risk case. Slovic et al. (1980) also found that experts seemed as prone to overconfidence 
as lay people, and Sjöberg (2004) found that experts made risk judgments on the basis of factors and thought structures that were similar to those of the public.

However, Sjöberg found a dramatic gap between experts' and managers' risk perceptions and those of the public and many politicians. According to Sjöberg, people want to avoid disastrous consequences no matter how small the experts assert their probability to be. He found that demand for risk mitigation was not strongly related to perceived risk but rather to the expected consequences of accidents or other unwanted events (Sjöberg, 2004).

Sandman (2009), in turn, concluded that there are three different risk communication paradigms, and these three risk communication paradigms have very little in common: (1) precaution advocacy-alerting apathetic people to serious risks; (2) outrage management-reassuring upset people about small risks; (3) crisis communication-guiding appropriately upset people through serious risks.

According to Sandman (1993; 2004), the key determinant of the public response to a hazard is not the magnitude of the hazard itself but the level of public outrage, or concern, about it. When people experience strong emotions, they have more difficulty hearing and processing information and are more likely to pay attention to negative rather than positive information. When it comes to high-outrage and low-hazard risks (outrage management), the key goal of communicators is to reduce public concern. The chief task of communication is to address the outrage, not to state or debate assessments of the hazard itself. According to Hooker et al. (2017), the best foil for outrage is to build sustainable public trust.

\section{Trust}

Trust helps us reduce uncertainty to an acceptable level and simplify decisions involving a large amount of information. The less we know about an activity, the more we need to rely on others to make decisions and the more our judgments about risk become a matter of trust (Savadori et al., 2004). Trust in control institutions can compensate for even a negative risk perception, and distrust may lead people to oppose risks even when they are perceived as small (Aven \& Renn, 2010). 
According to Aven and Renn (2010), information alone will never suffice to build or sustain trust. The first step in any communication effort is to find a common denominator, a common language, on which the communication can proceed and develop. Gaining institutional trust requires a continuous dialogue between risk managers, stakeholders, and representatives of the public. Participation creates confidence in the risk management process, and faith is important in risk management, particularly when it comes to risk from invisible hazards.

Trust is difficult and time-consuming to create and easily destroyed. Information that is received unproblematically at one point can be interpreted very differently under circumstances of mistrust. According to Sandman (2004), acknowledging uncertainty is a key recommendation for building sustainable public trust.

\section{Methods}

The data for the article were gathered through a research project studying risk and crisis communication concerning invisible hazards in Norwegian municipalities, in addition to a literature study of international research on risk communication, crisis communication, and invisible hazards. Risk and crisis communication is an important task for Norwegian municipalities, due to a statutory responsibility to inform and safeguard its citizens against hazards that may pose a risk to people and health.

The project was developed based on results from a pre-project carried out in five Norwegian municipalities in 2015 that focused on communication about radon (Solbakk et al., 2015). The results from the pre-project showed that risk communication about invisible hazards was a challenging task for the municipalities. Several of the municipalities had crisis communication plans, but they lacked routines and strategies that could be helpful before incidents occurred. Managing invisible hazards had been resource consuming for the municipalities, and the knowledge gained after incidents were not readily available to others.

In the current project we conducted six in-depth case studies in four Norwegian municipalities from 2017 to 2020. The studied 
municipalities were selected from the region of Western Norway. One of the case municipalities was a previous participant in the pre-project, and the remaining three municipalities were chosen based on the researchers' knowledge combined with a search for news stories in Norwegian media outlets. The case municipalities were also chosen to represent municipalities with different sizes and resources. In collaboration with the selected case municipalities, we then chose the six case studies which were incidents involving risk and crisis communication about invisible hazards that had occurred in the municipalities during recent years, had received media attention, and, in some cases, had led to conflict with stakeholders (i.e., those who are directly affected by the risk). The main purpose of the project was to help municipalities better understand the differences between visible and invisible hazards and evolve from mainly using reactive crisis communication to also using more proactive risk communication.

The case studies we chose for this project were as follows: Discovery of radon gas at a kindergarten and radon gas at a primary school (in a large municipality-approximately 24,000 inhabitants); mold spores at a primary school and asbestos fibers at a municipal swimming pool (in a large municipality-approximately 133,000 inhabitants); gas leaks at an oil and gas terminal (in a small municipality-approximately 4,700 inhabitants); and gas leaks at an oil refinery (in a medium-sized municipalityapproximately 15,000 inhabitants).

The data were gathered through seven focus group interviews and 10 individual in-depth interviews. We interviewed people responsible for communication about the incidents in our case studies, including communication managers, health directors, representatives from the occupational health services, councilmen, property managers, contingency planning managers, advisors, school principals, and kindergarten managers. We also interviewed stakeholders (parents and employees) and representatives from the media. Examples of the questions asked in the interviews were: How did the case evolve? How was risk communicated and who organized it? Why was this procedure chosen? Did you have plans/strategies in advance? Did you follow these? Was there anything you found challenging about communicating about this 
hazard? In your experience, is there a difference in communicating about visible and invisible hazards? Did you learn from previous experiences with communication about invisible hazards? Did you use this experience in the next case? What type of information about this hazard did you receive from the municipality? How do you perceive the communication from the municipality? In addition to the interviews, we conducted document studies of the municipalities' strategies, procedures, and routines for risk and crisis communication. This article focuses on results from parts of the gathered data material.

All interviews were recorded on audio file and transcribed in verbatim. The texts were then read by the three researchers (the authors of this article) who conducted the interviews and discussed and analyzed jointly between them. The main themes were identified, with an accompanying set of quotes from the interviews that substantiated the findings. The researchers' findings were then presented at a workshop for representatives from the case municipalities where the interviews were conducted. The representatives were given the opportunity to comment on and correct the researchers' findings, which served as a quality assurance of the results and helped to strengthen the reliability of the study. Finally, the representatives from the case municipalities were invited to read and comment on the completed analyses and conclusions as a last quality assurance of the research process.

Lastly, the COVID-19 crisis happened during the project period, and as the coronavirus is a clear example of an invisible hazard, we have added examples about COVID-19 to illustrate the challenges related to communication about invisible hazards.

\section{Results and Discussion}

The municipalities that participated in the research project had experienced incidents where communicating about invisible hazards had become challenging. Most of the municipalities saw a need for more knowledge about the differences between visible and invisible hazards and advice on how to better communicate the risk of invisible hazards to its citizens. The subsequent presentation of the results is organized according to the main themes 
that were identified during the analysis of the data material, with an accompanying set of quotes from the interviews that substantiates the findings. Furthermore, the results are discussed according to the theoretical framework presented in the Literature Review section.

\section{Differences between Risk and Crisis Communication about Invisible versus Visible Hazards}

In two of the studied cases, incidents with invisible hazards had led to serious conflicts between the municipalities and stakeholders. One case was the discovery of radon gas at a kindergarten, and the other was the discovery of mold at a primary school. In these cases, the stakeholders did not trust the experts hired by the municipalities, and they doubted and questioned the facts presented by the municipality.

In one of the cases, the parents hired their own experts, who came to different conclusions and disagreed with the municipality's experts. This led to negative publicity for the municipality in the media. A participant from the focus group interview with this municipality put it like this:

\section{“They mistrusted us, they didn't quite believe us.”}

In addition to complexity and uncertainty, the municipalities in our project experienced that some invisible risks led to more ambiguity than visible risks. There were disagreements about the causes of the hazards, the methods used for conducting measurements of the hazards, the interpretations of the results of the measurements, and/or the possible consequences of the hazards (interpretive ambiguity). Some risk estimates are based on uncertain inferences about incompletely understood processes. Experts can assess these risks differently, and sometimes there are no clearcut answers. As an example, there may be disagreement about whether the invisible hazard is actually the cause of the symptoms and illness that occurs, such as whether radon gas and asbestos fibers cause cancer or whether mold spores lead to asthma. It may take a long time for symptoms to show, and some may think other 
factors are the cause of the disease. As an example, a participant from a focus group interview with one of the municipalities said:

"And with asbestos, adverse effects might not appear until a long time has passed. And it is very uncertain, there are so many people that get cancer from different causes ( . . . )."

Moreover, the municipalities experienced disagreements about which values should be protected and which priorities should be made (normative ambiguity). For example, some people accepted that there were asbestos sheets in a building they worked in and knew that work was not being done that could cause harmful asbestos dust. Others considered this to be unacceptable.

The COVID-19 crisis has also been marked by both interpretive and normative ambiguity. As previously mentioned, the risk of the virus/disease and the measures taken to fight it have been heavily debated. There have been disagreements about where the virus came from, what caused it, possible consequences of the disease, and, also, which values should be protected, and which priorities authorities should take in the fight against the virus.

Furthermore, communication about the coronavirus provides an example of the unclear distinction between risk communication and crisis communication. Governments around the world were ill-prepared for the coronavirus, even though they knew pandemics were a threat. The rapid spread of the virus came as a surprise, and quickly turned into a crisis. Thus, governments' communication about the virus can be characterized as crisis communication: communication about something that has already happened. However, the COVID-19 crisis is long-lasting, and, as mentioned, there is still uncertainty about how the crisis will develop and what the possible means and measures to handle the crisis is. Thus, parts of the communication can also be characterized as risk communication: communication about something that might happen in the future.

The findings from our study confirm that whether a hazard is observable or not can affect how people perceive the risk, and invisible hazards may therefore represent additional challenges for risk and crisis communicators. Differences in risk perception exist 
regarding visible hazards as well, such as the risk of driving a car, flying a plane, the dangers of a ceiling collapse, and so forth. However, these visible hazards seldom lead to a communication crisis and strong concern among stakeholders and the public. In the research project, we found that visible hazards did not bring about as much uncertainty and ambiguity as invisible hazards. With visible hazards, one can see and possibly also perceive with one's other senses what the danger is; one can see the results of the hazard and what is being done about it. A participant from a focus group interview involving one of the municipalities emphasized this:

"But with invisible hazards you have this added element of fear, because after all, the documents we show and what we say in statements, they can't see it or feel it for themselves."

\section{Differences in Risk Perception and Social Amplification and Attenuation of Risk}

The results from our research project suggest that invisible hazards that are assessed as low risk by a municipality may become a crisis if the hazards invoke concern or fear among the stakeholders. A participant from a focus group interview with one of the municipalities said it this way:

\footnotetext{
"We need to recognize and understand that things that we perceive as trivial can still create fear."
}

In other cases, the municipalities expected strong concern and fear among stakeholders but there were no reactions. Hence, the results from our study can confirm the theories about risk amplification and attenuation. By this, we do not imply that it is possible to define a benchmark "real" risk that is determined by experts and around which public risk perceptions can subsequently become amplified or attenuated (Urquhart et al., 2017). Rather, we can simply demonstrate that the public's risk perception was amplified or attenuated in relation to experts' or managers' risk perception.

The results also confirm the risk perception theory that, in many cases, people are more concerned about risks if they affect others, especially children, rather than themselves. Risk perception 
research has identified several emotional characteristics (the affect heuristic) that bear directly on fear, and one of them is that risks to children evoke much more concern than the same risks to adults (Ropeik, 2013). According to Ropeik (2002; 2004), one of the important factors of risk perception is that when the risk is perceived to affect future generations (i.e., when kids are at risk), our fear is greater. For instance, asbestos in a workplace does not frighten us as much as asbestos in schools (Ropeik, 2002).

The two cases in our study with the most serious conflicts between the municipalities and stakeholders confirm the theory that people feel the most fear when their children are at risk. As an example of this, a participant from a focus group interview with one of the municipalities stated:

\section{“( . . ) And unlike the asbestos case that affected adults, this affected children. And then it gets much worse."}

However, the project results showed that this did not happen in every case. For example, one of the municipalities in the study had experienced a case where they found asbestos sheets in a school. The municipality wanted to close the school, but the parents objected. In this specific case, there were presumably other factors that played a more important role in the situation, such as keeping the local school open.

According to Fjaeran and Aven (2019), risks can develop, grow, and/or change character over time. Risks may be attenuated for years; they may then go through a brief or a long period of focus and attention, where some people intensify signals that are downplayed by others, before they are again forgotten, ignored or attenuated, and so on. It is important for the authorities to try to understand how the public feels about a risk, because this can play an important role in the way the public receives information. This point was highlighted by a participant from a focus group interview with one of the municipalities:

\footnotetext{
"But it's important to try to assess the situation, in all cases, how serious is the matter the first time you hear about it? Is this something that will blow over, or is this actually the beginning of a nightmare?"
} 
The results from the project's case studies showed examples of Sandman's (2009) three different risk communication paradigms (i.e., precaution advocacy, outrage management, and crisis communication). As previously mentioned, the chief task of communication is to address the outrage, not to state or debate assessments of the hazard itself. Thus, it is important for the authorities to be aware that there are different risk communication paradigms and different ways of handling communication about risk problems. A participant from a focus group interview with one of the municipalities put it this way:

\footnotetext{
"Yes, you have to face people's fears and worries, not just try to lessen it. You have to face it and also accept it-this has occurred, no one denies that."
}

According to Cairns et al. (2013), a message action plan that is based on knowledge of the expectations of audiences, existing relationships, and lines of communication is particularly valuable for crisis communications teams. This may be complemented by preemptive communication strategies, such as the dissemination of updated information on educational websites and newsletters before emergency situations occur to prepare key audiences for possible eventualities. By presenting risk communication messages long before the emergence of a crisis event, the probability of its occurrence might be reduced. Communicators also need to be prepared to modify messages if circumstances change and have an awareness of the active role participants play in communicative processes. This is also in line with the World Health Organization (WHO)'s Outbreak Communication Planning Guide:

Proactive communication of a real or potential health risk is crucial in alerting those affected and minimizing an infectious disease threat. Announcing early-even with incomplete information-prevents rumors and misinformation. The longer officials withhold information, the more frightening the information will seem when it is eventually revealed, especially if it is revealed by an outside source. (WHO, 2008) 
Late announcements will erode people's trust in the ability of the authorities to manage the hazard. This was underlined by a participant from a focus group interview with one of the municipalities:

"And if you haven't made sure that you give enough information beforehand, then there will be a lot of speculation. So, being proactive, and being as open as you can, as clear as you can, as early as possible, I think is very important."

According to Hooker et al. (2017), public reactions during the initial period of a risk event have costs and may be at odds with what experts recommend. However, they are often transient. It is more useful to plan to accommodate early overreactions to allow them to subside as swiftly as possible. Communicating early and often may risk generating extra media attention, and reveal problems that people have never imagined before, but at the same time it enables the authorities to capture the issue.

\section{Involving the Stakeholders}

Participatory dialogue is especially useful when developing risk and crisis communication strategies (Cairns et al., 2013; Glik, 2007). It is important to actively engage with stakeholders and avoid one-way communication between experts and the public. This can serve as an act of empowerment for stakeholders. The process of receiving consequential and pertinent information raises awareness of the risks pertaining to a specific issue. This, in turn, gives stakeholders the opportunity to make informed choices and acquire a sense of control over their own well-being (Cairns et al., 2013).

Several of the municipalities that participated in the project had experienced this. As one of the participants from a focus group interview with one of the municipalities stated:

\footnotetext{
"( $\ldots$ ) (M)y impression is that if you can manage to get the stakeholders involved fast, and make them feel that they are taken seriously, that they get information early, then you can save yourself a lot of trouble $(\ldots)$ they are very interested in getting involved."
} 
Fischoff (1995) also found that involving the stakeholders during a process of risk communication was a good idea. This can show the safety measures taken and possibly dampen the social amplification of minor risks, as well as to generate concern where it is warranted.

\section{Coordination and a Common Stance}

The municipalities also emphasized that when communicating about a risk it was important to coordinate and cooperate between different departments and/or persons that had a responsibility for handling the invisible hazard. Everyone involved should take responsibility for the risk and/or crisis communication and not wait and assume that another department would take care of the problem. They should meet as soon as possible, inform each other, and agree on a joint message and a common stance. A participant from a focus group interview with one of the municipalities put it this way:

\footnotetext{
“( ... ) But, working across different disciplines, I think that was one of the things that helped us find a good solution to this. So, this is a matter that can be a point of concern when public administration needs to handle something, namely that people don't talk to each other across different departments and disciplines."
}

According to Christensen and Lægreid (2020), an important part of the Norwegian authorities' communication strategy during the COVID-19 crisis was that political, administrative, and professional executives appeared to take a common stance. Thus, an important lesson from meaning-making in a crisis situation is the importance of formulating a shared, sensible, persuasive, and common message in the wake of a crisis; working together to make a credible picture of what is going on; planning how to handle it; and communicating this understanding to the general public (Boin et al., 2019; Christensen \& Lægreid, 2020).

\section{Trust}

As found in many studies of risk and crisis communication, the results from the research project showed that it was important 
for the municipalities to be honest and try to establish trust. As Hooker et al. (2017) state, the best foil for outrage is to build sustainable public trust. When facing trade-offs in probable outcomes from communication it is always best to choose strategies to maintain or build trust, even at the cost of initial overreactions. One of the participants from the focus group interview with parents at a school said:

"Honesty. It would be better if they had said: 'We do not have enough knowledge about this, but we will do the best we can, and call you back in a week.' But no one would take the responsibility."

As another example, in relation to genetically modified organisms, Marris (2001) found that focus group participants wanted a more realistic assessment of risks by authorities. The participants found expert statements that asserted that there were no risks to be disconcerting and untrustworthy. The participants in the focus groups accepted that it was necessary to counterbalance risks with benefits but felt that they were not told how this judgment had been made and were not invited to participate in the process. Therefore, they suspected that economic interests had overridden health and environmental considerations.

Results from the research project also showed that it was important for the municipalities to quickly appoint a contact person that people could approach if they had fears or worries, or just needed more information. The contact person should have good communication skills and be knowledgeable, empathetic, and humble. The contact person should also acknowledge any uncertainty. A participant from a focus group interview with one of the municipalities said:
"( $\ldots$. If there is no contact person, then people may be left won- dering: What do I do now? What should I do? Can I leave? Should I investigate? How dangerous is this?"

According to Fjaeran and Aven (2019), adopting an uncertainty-based perspective on risk may inject some amplification into risk assessment and management processes. However, in relation to risk problems characterized by complexity, uncertainty, 
and ambiguity, an uncertainty-based understanding of risk can improve assessment and management processes and practice in ways that can prevent attenuation from occurring and/or spreading. If attenuated risks are revealed, for instance following an unanticipated risk event, accident or exposure to camouflaged risk information or new knowledge, risk tends to become highly amplified, resulting in significant and far-reaching effects. Some risk amplification at an early stage of such processes, making the invisible more visible, may reduce the degree of later amplification and the associated consequences.

According to Andrade et al. (2020), disasters present unique challenges given their inherent uncertainty, and facts can be elusive in rapidly evolving disaster contexts. "Information vacuums" can create opportunities for the public to speculate, make inferences to explain gaps, question motives, generate rumors, or propagate unverified or false information in an attempt to reconcile perceived incongruences (Andrade et al., 2020; Hagar, 2013). The media often plays a major role in disseminating the authorities' meaning-making and communication with citizens, and managing media relations is an important part of authorities' communication strategies (Christensen \& Lægreid, 2020).

It is also important to show the stakeholders and public that measures aimed at reducing the risk are implemented as fast as possible. According to Hooker et al. (2017), public concerns are most effectively allayed by actions rather than words. People want to know what is being done to actively mitigate the risk, not just be reassured. A participant from a focus group interview with one of the municipalities explained it this way:

\footnotetext{
“( . . ) I think we were too uncertain in our communication, we waited too long to take action; are they implementing measures, or are they trivializing it, underestimating the danger?"
}

As an example, the Norwegian government hesitated and took a wait-and-see approach during the early stages of the coronavirus outbreak in 2020 (Christensen \& Lægreid, 2020). Consequently, the authorities were criticized in the media for reacting too late and for being too defensive. This led to widespread confusion among the public, and people were unsure of how serious the risk really 
was. However, on March 12, 2020, the Norwegian government implemented draconian measures to combat the virus (Christensen \& Lægreid, 2020), including closing down kindergartens and schools and closing the borders. According to articles in the Norwegian media, the main response from the public immediately after this decision was that it was good to finally receive some clear and unambiguous guidelines from the authorities.

\section{Conclusion}

It is important for those responsible for risk and crisis communication to be aware of the complexity, uncertainty, and ambiguity that characterize invisible hazards, which can vary from case to case, depending on the context. People's reactions to invisible hazards are often influenced by guesswork and different interpretations. Risk and crisis communicators need to be aware of possible differences in risk perception when they plan how to communicate about risks. Social amplification and attenuation of risk are some of the factors that can explain why there are such differences in risk perception related to invisible hazards, both between risk experts/managers and the public, and between different groups of citizens. Communicators should be aware that different risk problems thus require different responses.

Creating trust and being honest are very important for all risk and crisis communication and even more important when it comes to invisible hazards. This is because the less we know about a hazard, the more we need to rely on others to make decisions and the more our judgments about risk become a matter of trust (Savadori et al., 2004). According to Hooker et al. (2017), the governing aphorism for successful risk communication is that people need to hear that you care before they really care about what they hear, and demonstrating that you care far beyond a performance of concern. However, if this is inauthentic it can generate mistrust. Successful risk and crisis communication require the building and sustaining of public trust.

Furthermore, it is important to coordinate and cooperate between different departments and/or persons that have a responsibility for handling the invisible hazard and agree on a joint 
message and common stance. Stakeholders, and in some cases the public, should be involved and dialogue should be facilitated. Involving the stakeholders can run the risk of revealing problems that people have never imagined before, and those responsible for risk and crisis communication want to avoid creating unnecessary concern or fear. However, it can also show which safety measures are taken, perhaps dampen the social amplification of some risks, and generate concern where it is warranted (Fischoff, 1995).

\section{ORCID}

Ruth Ø. Skotnes (1) https://orcid.org/oooo-0001-5329-7942

Kåre Hansen (1) https://orcid.org/oooo-0003-2442-8952

Anne V. Krøvel 다 https://orcid.org/oooo-0003-2108-2933

\section{References}

Andrade, E. L., Barrett, N. D., Edberg, M. C., Rivera, M. I., Latinovic, L., Seeger, M. W., Goldman-Hawes, A., \& Santos-Burgoa, C. (2020). Mortality reporting and rumor generation: An assessment of crisis and emergency risk communication following Hurricane Maria in Puerto Rico. Journal of International Crisis and Risk Communication Research 3(1), 15-48. https://doi. org/10.30658/jicrcr.3.1.2

Aven, T., \& Renn, O. (2010). Risk management and governance: Concepts, guidelines and application. Springer. https://doi. org/10.1007/978-3-642-13926-0

Boin, A., Brown, C. \& Richardson, J. A. (2019). Managing Hurricane Katrina: Lessons from a Megacrisis. Louisiana State University Press.

Boin, A., Ekengren, M., \& Rhinard, M. (2020). Hiding in plain sight: Conceptualizing the creeping crisis. Risk, Hazard \& Crisis in Public Policy 11(2), 116-138. https://doi.org/10.1080/ 25741292.2020.1823670

Cairns, G., de Andrade, M., \& MacDonald, L. (2013). Reputation, relationships, risk communication and the role of trust in the prevention and control of communicable disease: A review. Journal of Health Communication, 18(12), 1550-1565. https:// doi.org/10.1080/10810730.2013.840696 
Christensen, T., \& Lægreid, P. (2020). The coronavirus crisisCrisis communication, meaning-making, and reputation management. International Public Management Journal. https:// doi.org/10.1080/10967494.2020.1812455

DSB. (2014). Direktoratet for Samfunnssikkerhet og Beredskap (DSB). Risiko-og krisekommunikasjon.

Fischoff, B. (1995). Risk perception and communication unplugged: Twenty years of process. Risk Analysis, 15(2), 137-145. https:// doi.org/10.1111/j.1539-6924.1995.tboo308.x

Fjaeran, L., \& Aven, T. (2019). Making visible the less visible-How the use of an uncertainty-based risk perspective affects risk attenuation and risk amplification. Journal of Risk Research. https://doi.org/10.1080/13669877.2019.1687579

Glik, D. (2007). Risk communication for public health emergencies. Annual Review of Public Health, 28, 33-54. https://doi. org/10.1146/annurev.publhealth.28.021406.144123

Hagar, C. (2013). Information vacuums. In K. B. Penuel, M. Statler, \& R. Hagen (Eds.), Encyclopedia of Crisis Management, 527529. Sage Publications.

Hallman, W. (2016). 8 interventions and risk communication, national academies of sciences, engineering, and medicine, health risks of indoor exposure to particulate matter: Workshop summary. The National Academies Press. https:// doi.org/10.17226/23531

Hevey, D. (2017). Radon risk and remediation: A psychological perspective. Public Health 5(63). https://doi.org/10.3389/ fpubh.2017.00063

Hooker, C., Capon, A., \& Leask, J. (2017). Communicating about risk: Strategies for situations where public concern is high but the risk is low. Public Health Res Pract., 27(1), e2711709. https://doi.org/10.17061/phrp2711709

Kasperson, J. X., \& Kasperson, R. E. (2005). The social contours of risk-Publics, risk communication \& the social amplification of risk. Earthscan. https://doi.org/10.1111/j.14678306.2007.00547.x 
Kasperson, R. E. (2012). The social amplification of risk and lowlevel radiation. Bulletin of the Atomic Scientists, 68(3), 59-66. https://doi.org/10.1177/0096340212444871

Kasperson, R. E., Renn, O., Slovic, P., Brown, H. S., Emel, J., Goble, R., Kasperson, J. X., \& Ratick, S. (1988). The social amplification of risk: A conceptual framework. Risk Analysis 8(2), 177-187. https://doi.org/10.1111/j.1539-6924.1988.tbo1168.x Lofstedt, R. (2003). Risk communication: Pitfalls and promises. European Review 11(3), 417-435. https://doi.org/10.1017/ $\mathrm{S}_{106279870300036 \mathrm{X}}$

Marris, C. (2001). Public views on GMOs: Deconstructing the myths. European Molecular Biology Organization (EMBO) Reports (Vol. 2, No. 7, pp. 545-548. https://doi.org/10.1093/ embo-reports/kve142

Renn, O. (2006). Risk communication-Consumers between information and irritation. Journal of Risk Research 9(8), 833849. https://doi.org/10.1080/13669870601010938

Ropeik, D. (2002). Understanding factors of risk perception. Nieman Reports Winter 2002. https://web.archive.org/ web/20200118071819/https://niemanreports.org/articles/ understanding-factors-of-risk-perception/

Ropeik, D. (2004). The consequences of fear. EMBO Reports (Vol. 5, Special Issue). https://doi.org/10.1038/sj.embor.7400228

Ropeik, D. (2013). How society should respond to the risk of vaccine rejection. Human Vaccines Immunotherapeutics 9(8), 1815-1818. https://doi.org/10.4161/hv.25250

Sandman, P. M. (2012). Responding to community outrage: Strategies for effective risk communication. AIHA Press. http:// psandman.com/media/RespondingtoCommunityOutrage.pdf Sandman, P. M. (2004). Acknowledging uncertainty, risk= hazard + outrage. The Peter Sandman Risk Communication Website. https://web.archive.org/web/20110108031851/http://www. psandman.com/col/uncertin.htm

Sandman, P. M. (2009, Oct. 20). Trust the public with more of the truth: What I learned in 40 years in risk communication. The 2009 Berreth Lecture, presented to the National Public Health Information Coalition, Miami Beach FL. 
Savadori L., Savio, S., Nicotra, E., Rumiati, R., Finucane, M., \& Slovic, P. (2004). Expert and public perception of risk from biotechnology. Risk Analysis 24(5), 1289-1299. https://doi. org/10.1111/j.0272-4332.2004.00526.x

Schleibinger, H., Keller, R., \& Rüden, H. (2004). Indoor air pollution by microorganisms and their metabolites. In P. Pluschke (Ed.), Indoor Air Pollution. The Handbook of Environmental Chemistry, $4 \mathrm{~F}$ (pp. 149-177). Springer-Verlag. https://doi. org/10.1007/b94834

Sjöberg, L. (2004). Principles of risk perception applied to gene technology. European Molecular Biology Organization (EMBO) Reports (5 Special Issue, pp. 47-51). https://doi.org/10.1038/ sj.embor.7400258

Skotnes, R. Ø., Hansen, K., \& Krøvel, A. V. (2020). Risiko-og krisekommunikasjon om usynlige farer, Report 13-2020, NORCE Social Science.

Slovic, P., Finucane, M. L., Peters, E., \& MacGregor, D. G. (2007). The affect heuristic. European Journal of Operational Research 177, 1333-1352. https://doi.org/10.1016/j.ejor.2005.04.006

Slovic, P., Fischoff, B., \& Lichtenstein, S. (1978). Accident probabilities and seat belt usage: A psychological perspective. Accident Analysis and Prevention, 10, 281-285. https://doi. org/10.1016/0001-4575(78)90030-1

Slovic, P., Fischhoff, B., \& Lichtenstein, S. (1980). Facts and fears: Understanding perceived risk. In R. C. Schwing \& W. A. Albers (Eds.), Societal Risk Assessment. General Motors Research Laboratories (pp. 181-216). Springer. https://doi. org/10.1007/978-1-4899-0445-4_9

Solbakk, M., Ford, E. P., \& Krøvel, A. V. (2015). Regionalt Forskningsfond Vestlandet (RFFV): Forprosjekt 241522: Kommunikasjon av usynlige farer-utfordringer knyttet til radon i vestnorske kommuner.

Tversky, A., \& Kahneman, D. (1974). Judgment under uncertainty: Heuristics and biases. Science, 185, 1124-1131. https://doi. org/10.1126/science.185.4157.1124 
Urquhart, J., Potter, C., Barnett, J., Fellenor, J., Mumford, J., \& Quine, C. P. (2017). Expert risk perceptions and the social amplification of risk: A case study in invasive tree pests and diseases. Environmental Science and Policy 77, 172-178. http:// dx.doi.org/10.1016/j.envsci.2017.08.020

Weick, K. E. (2001). Making sense of the organization. Blackwell Business.

Weinstein, N. D., Klotz, M. L., \& Sandman, P. M. (1988). Optimistic biases in public perceptions of the risk from radon. Am J Public Health 78, 796-80o. https://doi.org/10.2105/AJPH.78.7.796

WHO. (2008). World Health Organization Outbreak Communication Planning Guide, 2008 Edition. 